\title{
Teaching of the sensitive examinations: An international survey
}

\author{
Selena A. Hunter ${ }^{1,2^{\star}}$, Alice McLachlan ${ }^{3}$, Takayoshi Ikeda ${ }^{4}$, Michael J. Harrison ${ }^{1}$, \\ Duncan C. Galletly ${ }^{1}$ \\ ${ }^{1}$ Department of Surgery and Anaesthesia, University of Otago, Wellington, New Zealand; \\ *Corresponding Author: selena.hunter@otago.ac.nz \\ ${ }^{2}$ Department of Anaesthesia, Wellington Hospital, Capital and Coast District Health Board, Wellington, New Zealand \\ ${ }^{3}$ Wellington Hospital, Capital and Coast District Health Board, Wellington, New Zealand \\ ${ }^{4}$ Dean’s Department, University of Otago, Wellington, New Zealand
}

Received 29 October 2013; revised 12 December 2013; accepted 5 January 2014

Copyright (C) 2014 Selena A. Hunter et al. This is an open access article distributed under the Creative Commons Attribution License, which permits unrestricted use, distribution, and reproduction in any medium, provided the original work is properly cited. In accordance of the Creative Commons Attribution License all Copyrights @ 2014 are reserved for SCIRP and the owner of the intellectual property Selena A. Hunter et al. All Copyright (C) 2014 are guarded by law and by SCIRP as a guardian.

\section{ABSTRACT}

Background: The teaching of the sensitive examinations-i.e. that of the female breast, female pelvis, female and male rectum and male genitalia-is a challenging part of the undergraduate curriculum. There are no studies to date detailing how national and international medical schools teach all of these examinations. Purposes: This research sought to document the teaching strategies used by national and international medical schools regarding the sensitive examinations. Methods: The sensitive examinations surveyed are the: 1) Female breast; 2) Female pelvis; 3) Male genitalia; 4) Female and male rectum. The term "female sensitive examinations" is used to refer to female breast and female pelvis examinations. This was a questionnaire study, which polled national New Zealand medical schools as well as international medical schools. Questions included: a) sensitive examination teaching method; b) stress reduction strategies; c) perceived graduating student confidence. Results: A total of 104 medical schools participated in this survey in 2010. Artificial manikin usage was the most common technique utilized for each sensitive examination (60\% of all schools, $95 \% \mathrm{Cl} 55 \%-65 \%)$, whether as the sole teaching method or in combination with other methods. The next most common technique was teaching associates $(49 \%$ of schools, 95\% Cl 44\% - 54\%). The female breast and pelvis sensitive examinations used the teaching associate program more frequently than the male genital examination and female and male rectal examination. Regardless of teaching method, most schools believed their graduating students were confident. Stress management teaching was used in most schools, in conjunction with teaching associate sessions. Conclusion: Manikins were the most commonly used teaching component of a teaching programme on sensitive examinations. Irrespective of teaching method, most schools believed their students were confident upon graduation.

\section{KEYWORDS}

International; Sensitive; Examinations; Teaching

\section{INTRODUCTION}

The teaching of the "sensitive" examinations-i.e. that of the female breast (FB), female pelvis (FP), male genitalia (MG) and female and male rectum (FMR) - is a uniquely challenging part of the undergraduate curriculum. In the author's opinion, these examinations must be approached with much greater sensitivity than the other physical examinations and with more thought to the doctor-patient interaction. Students may be embarrassed or concerned about patient discomfort and thus they may perform the examinations in a rushed manner [1]. It may be difficult for clinicians to guide students, especially with the rectal and pelvic examinations, as the structures of interest are hidden [1]. There is also inherent difficulty in achieving student confidence in the sensitive examina- 
tions with high clinician workload and adhering to proper informed patient consent [2,3]. It remains difficult to ensure adequate quantity and quality of training, and male students may be disadvantaged with respect to the female sensitive examinations [4]. In addition anaesthetised women have occasionally been subjected to student vaginal examination without specific consent [2].

Teaching of the sensitive examinations may involve several different methods, including artificial manikins, real patients, actors, anaesthetized women, peer physical examination and teaching associates or simulated patients. Manikins allow repetition, and may provide a close approximation of reality especially when used in combination with a simulated patient [5]. Third year medical students become more competent and confident in breast examination when training using a strap-on breast model [6].

Internationally there has been a shift towards the use of the teaching associate program especially for examination of the female pelvis. This involves utilizing paid gynaecological teaching associates (GTAs) [1]. These women are trained to teach examinations using their own bodies as the model, usually under the supervision of an appropriately qualified doctor. The advantage of this program over real patients is the interactive feedback that students receive whilst performing the examination, regarding clinical and communication skills [7], from both the GTA and the supervising physician [8]. There is less time restriction, and the session can be focused on student learning as well as sensitive examination "etiquette" [1]. Studies examining such programs have reported lower student stress, better preparation for the sensitive examinations of real patients, increased proficiency with communication [9] and increased student confidence [8, 10-12]. The TA program has also been used for the teaching of the male genital examinations, in which the term is "Urological Teaching Associate", as well as the female and male rectal examinations. These patient-instructors are also known as "standardized" or "simulated" patients, especially in the non-gynaecological sensitive examinations including the breast and rectal examinations.

Real patients (RP) are obviously the most authentic method to learn the sensitive examinations, even compared with teaching associates [9]. Studies have shown that students consider real patient interactions more instructive than TA interactions [9]. The frequent use of real patients enables students to differentiate normal and pathological findings [9]. However RP sensitive examinations may involve less acquisition of communication skills [9], less opportunities if patients are unwilling [9] and exposure of the patient to the novice learning curve [13]. These examinations also require informed consent and appropriate medical supervision.

Several other methods exist in terms of teaching the "sensitive" examination, and these were not explored in this study. These include pelvic examination on consented anaesthetized women whilst in surgery, and peer physical examination. The former are often utilized for teaching the vaginal examination, after sessions using manikins, in addition to real patients in clinics [2]. This method of teaching can be difficult due to ethical considerations in the context of time constraints, as specific written informed consent needs to be obtained prior to sedation and anaesthesia. Recent studies show that the rates of such examinations in anaesthetized or sedated patients without adequate patient consent are still significant, ranging from $9 \%-25 \%[2,14]$. Some students require more commitment to seek consent. Other obstacles include supervising clinician disinterest or insufficient time [2]. However many students do gain educational benefit from this method of teaching [2]. Further research could be directed at surveying the use of anaesthetized women for pelvic examinations. Peer physical examination is another teaching format, whereby students perform examinations on each other within a controlled environment. Studies have shown that the majority of students are comfortable with non-sensitive peer physical examinations, i.e. excluding breast, genital and rectal examinations, due to the greater practice opportunity and peer feedback [15-18]. Suggested peer examination in the "sensitive" areas of breast and genitalia has drawn negative responses from students [17].

Other studies in this field have surveyed individual medical school's staff and students, or ask questions regarding only one sensitive examination subtype or stress reduction technique $[1,4,5,9]$. There has been no study to date surveying a large number of international medical schools regarding the teaching of each sensitive examination.

The aim of this present study, which was achieved, was to document the teaching strategies used by many national and international medical schools, regarding the teaching of all of the sensitive examinations. We asked questions pertaining to teaching method, stress reduction strategies and medical schools' perception of the confidence of their graduating students.

\section{METHOD}

Category B Ethical Approval was obtained from the University of Otago Human Ethics Committee. A questionnaire was developed, including both quantitative and qualitative questions regarding the teaching of student breast, pelvic, genital and rectal examinations. There was no preceding pilot survey. For a full copy of this questionnaire please email the corresponding author. We in- 
cluded specific questions regarding teaching stress management techniques.

We obtained the email addresses of medical schools in the USA and Canada on the American Association of Medical Colleges website (www.aamc.org), and for other international medical schools, we obtained the addresses from the Institute of International Medical Education website (www.iime.org). Regarding the mdical schools that offer a Doctor of Medicine or Bachelor of Medicine and Bachelor of Surgery, there are 17 medical schools in Canada, 141 in the United States, 32 in the United Kingdom, 19 in Australia, 8 in South Africa, one in Fiji, two in Hong Kong, two in Singapore and two in New Zealand. We were able to mae initial contact with 195 of these224 schoolsin this survey.

Initial contact entailed emailing the Dean of each Medical School, requesting the details of an appropriate contact who could assist with the project. If there was no response we sent a second email to the Education Dean or equivalent contact. If this failed to generate a response we attempted to contact an appropriate member of the School of Medicine. After three attempts no further contact was sought.

An appropriate contact was defined as the school staff member responsible for teaching examination skills. This was usually staff from the obstetrics and gynaecology department, with some surveys completed by the urologists or the general surgeons. Often the first contactable staff member circulated the survey to other departments to ensure accuracy of answers; for example the teaching staff in the obstetrics and gynaecology department filled in the questions on the teaching of the female pelvis examination but then sent the survey to the urology department to complete questions on the teaching of the male genitalia exam.

We analysed the data with SPSS statistical software version 16.0 for Mac. Microsoft Excel 2004 version
11.5.5 for Mac was used tocalculate 95\% confidence intervals using Fisher's exact method. Further statistical analysis of the tables and figures was performed using $\mathrm{R}$ 2.15.0. [8]

\section{RESULTS}

Out of the 195 schools initially contacted, 125 supplied an appropriate contact. 104 of these returned their completed surveys in time to be included in the analysis. The response rate and representativeness per country according to total population is shown in Table 1.

Artificial manikins was the most commonly used method to teach the female sensitive examinations (female breast and pelvis) (70\% (CI 60\% - 79\%) and 64\% (CI $54 \%-74 \%$ ) of medical schools respectively). However teaching associate usage was very prominent, with $52 \%$ (CI $42 \%-62 \%$ ) and $61 \%$ (CI 51\% - 71\%) of schools surveyed using them to teach the female breast and pelvis respectively.

The manikin programme was also the most commonly used teaching method with regard to the male genital examination, (50\% of medical schools (CI 39\% - 60\%). However the frequency of the methods used to teach the male genital examination was quite evenly spread, with $50 \%(39 \%-60 \%), 47 \%$ (CI 37\% - 57\%) and 44\% (CI $35 \%-55 \%)$ of schools using manikins, teaching associates and real patients respectively.

Teaching of the female and male rectal examinations relied mostly on manikins, (65\% (CI 54\% - 74\%), while teaching associates and real patients comprised $42 \%$ (CI $33 \%-53 \%)$ and $44 \%$ (CI 35\% - 55\%) of schools respectively)

Sensitive examination subgroup analysis by country yielded varying results (Figures 1-4).

Most schools had specific teaching to deal with the emotive aspects of the sensitive exam. A third said that it

Table 1. Total population, number of schools initially contacted and number returning completed surveys according to country.

\begin{tabular}{ccccc}
\hline Country & Population (2009) & No. of medical schools in country & No. of schools contacted & No. of schools returning completed survey \\
\hline Australia & $21,262,641$ & 19 & 12 & 11 \\
United Kingdom & $61,113,205$ & 32 & 18 & 17 \\
United States & $307,212,123$ & 141 & 2 & 63 \\
Hong Kong & $7,055,071$ & 2 & 2 & 1 \\
Singapore & $4,657,542$ & 2 & 7 & 2 \\
South Africa & $49,052,489$ & 8 & 16 & 9 \\
Canada & $33,487,208$ & 17 & 1 & 0 \\
Fiji & 944,720 & 1 & 2 & 2 \\
New Zealand & $4,213,418$ & 2 & & 2 \\
\hline
\end{tabular}



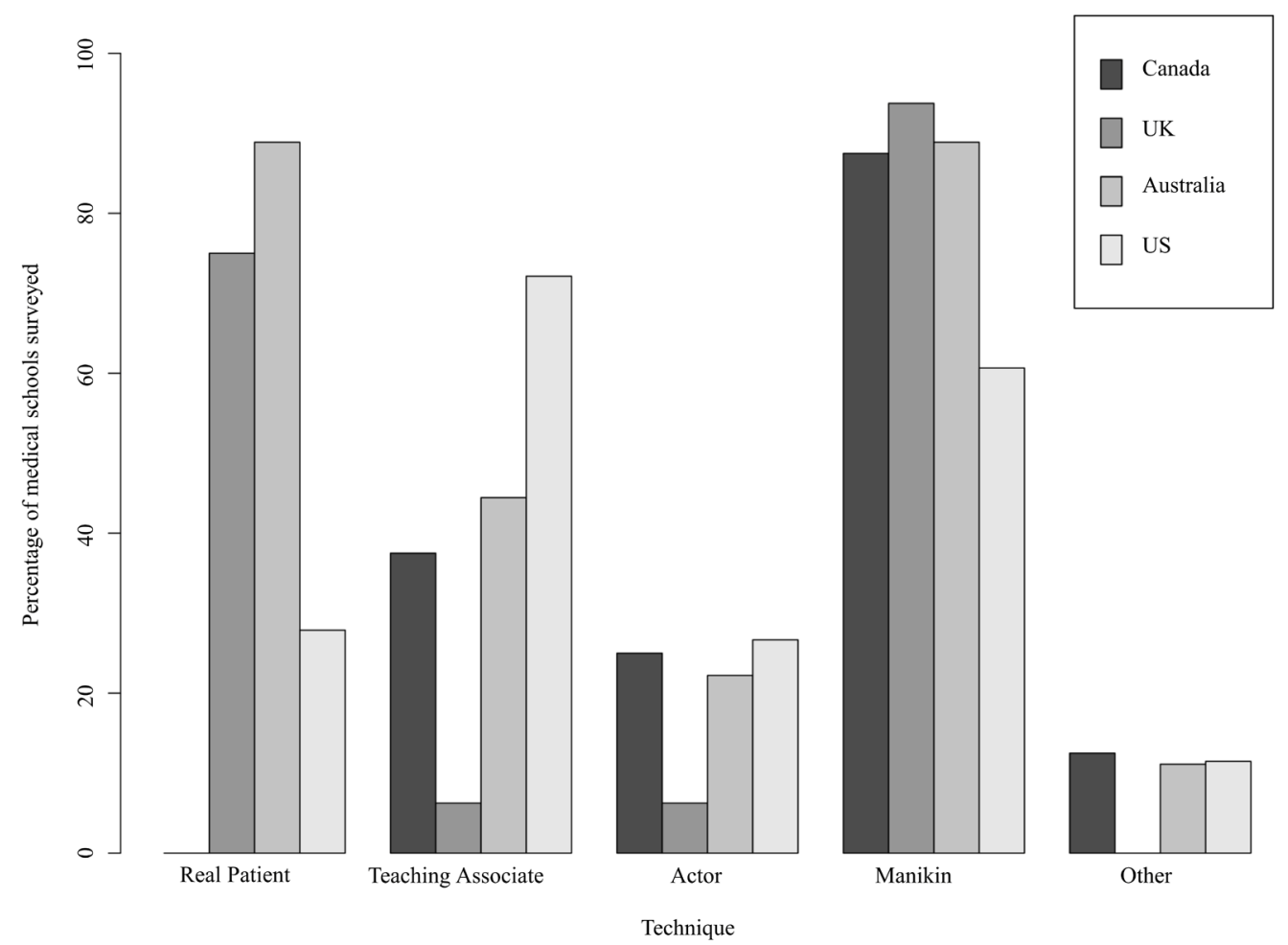

Figure 1. Techniques used to teach breast examination according to country. The percentage of surveyed medical schools utilising the various techniques (real patient, teaching associate, actor, manikin and other) to teach the breast examination according to country.

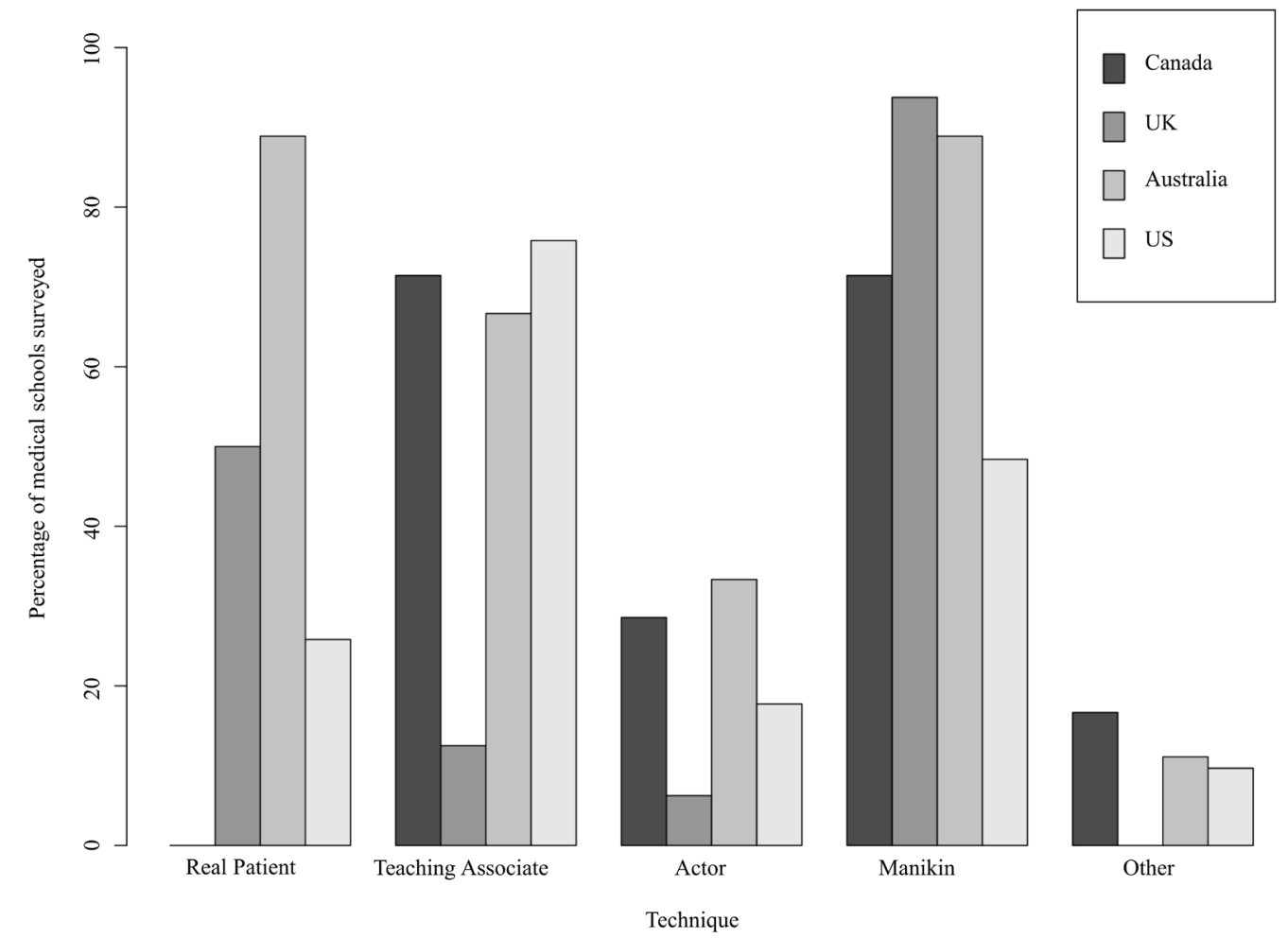

Figure 2. Techniques used to teach pelvic examination according to country. The percentage of surveyed medical schools utilising the various techniques (real patient, teaching associate, actor, manikin and other) to teach the pelvic examination according to country. 


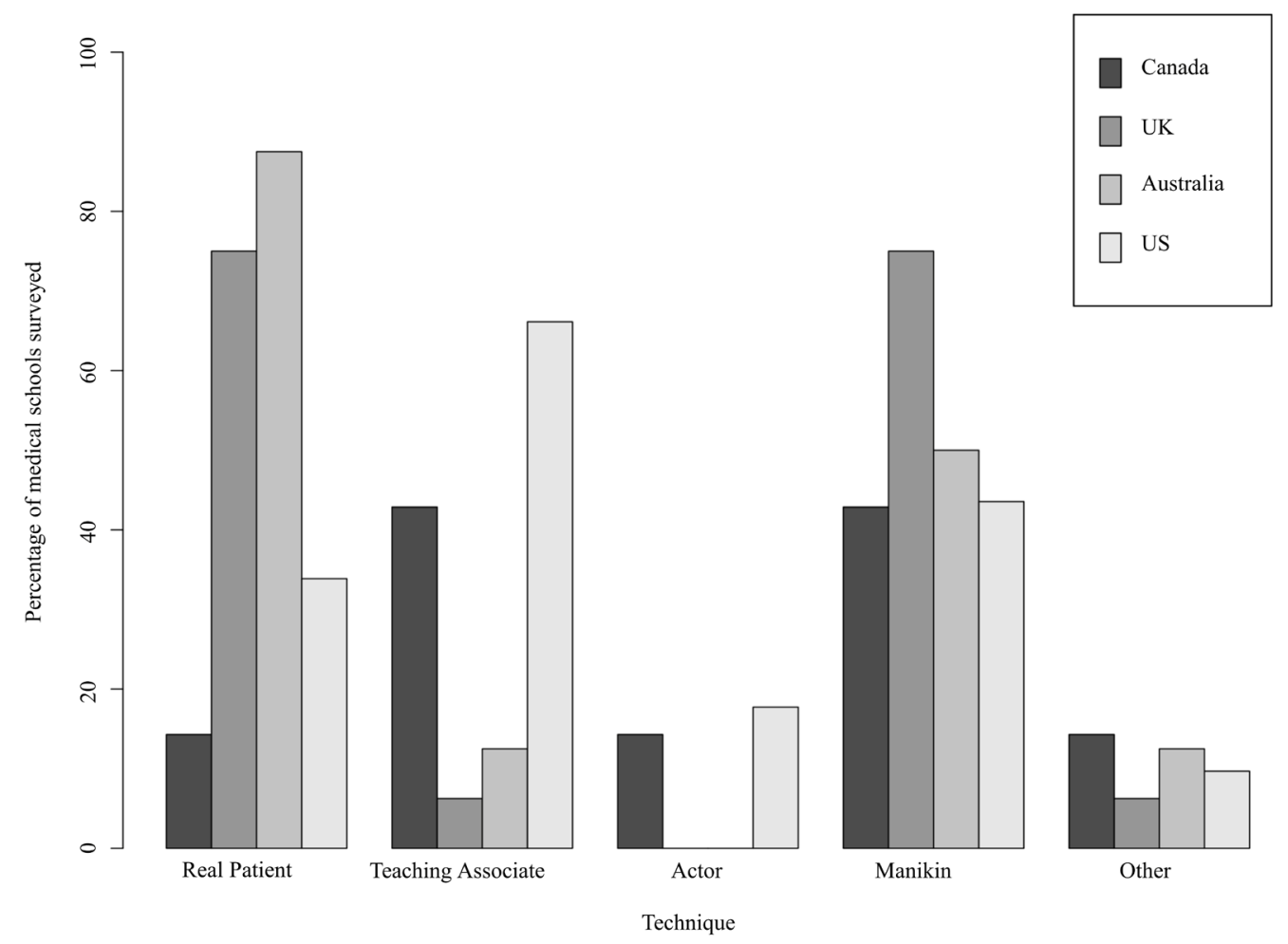

Figure 3. Techniques used to teach male genital examination according to country. The percentage of surveyed medical schools utilising the various techniques (real patient, teaching associate, actor, manikin and other) to teach the male genital examination according to country.
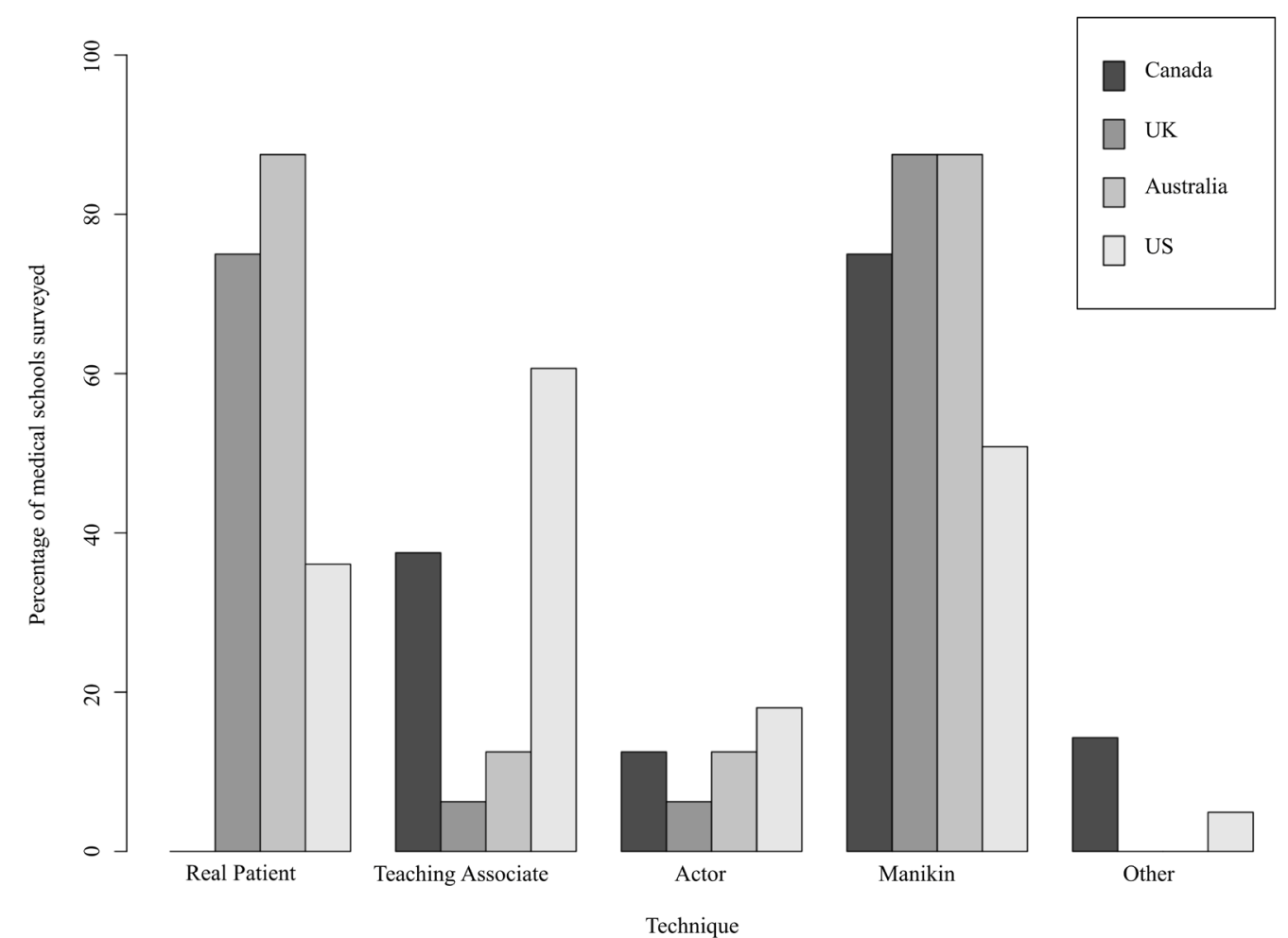

Figure 4. Techniques used to teach male and female rectal examination according to country. The percentage of surveyed medical schools utilising the various techniques (real patient, teaching associate, actor, manikin and other) to teach the male and female rectal examination according to country. 
was taught in conjunction with the TA sessions, either before or during the small group sessions. Other methods included videos, lectures, communication skills and via an introductory clinical skills sessions. However, 15\% said that they had minimal or no teaching regarding this topic. Many mentioned what points they taught their students but not the way in which they did the teaching.

Regarding practice of the sensitive examinations after the initial teaching session, we asked schools whether there were organized or opportunistic practice sessions. The majority of schools used opportunistic practice for each sensitive examination subgroup. The figures are: female sensitive examinations (female breast and pelvis), 65\% (CI 54\% - 74\%) and 66\% (CI 56\% - 76\%) respectively; male genitalia examination-81\% (CI 72\% - 88\%) and female and male rectum-75\% (CI 65\% - 83\%). Practice opportunities for both opportunistic and organized sessions arose most commonly in breast clinics and during the obstetrics and gynaecology rotation. It was noted that it was possible for students to "avoid" practicing such examinations. There were no formal questions about whether a student had to be "signed off" on the number of practice sessions, regardless of organized or opportunistic.

With respect to the number of examinations performed by graduation, the results per sensitive examination sub- type are as depicted below (see Figure 5).

Regarding perceived confidence in the sensitive examinations upon graduation, all schools believed their students were confident in each sensitive examination by the time they graduated.

Perceived confidence by graduation with respect to teaching method showed no significant differences (based on a 4-sample test for equality of proportions with a p-value > 0.1.) Most schools believed that their students attain confidence with their method of teaching, with a mean of $81 \%$ (range of $76 \%-87 \%$ ). SD $=4.6$ ). Respondents noted informally that a) females obtained more experience of the female examination, b) that confidence didn't necessarily mean competence, and c) that potentially there was a large inter-student variation with respect to clinical exposure. There was no student survey analyzing confidence by graduation in the sensitive examinations.

\section{DISCUSSION}

Our survey of national and international medical schools shows that the predominant mode of teaching the sensitive examinations is via artificial manikins. These were either used alone, or with standardized patients (lay people acting as patients) or as part of the teaching associate sessions. The reason that manikins are so frequently
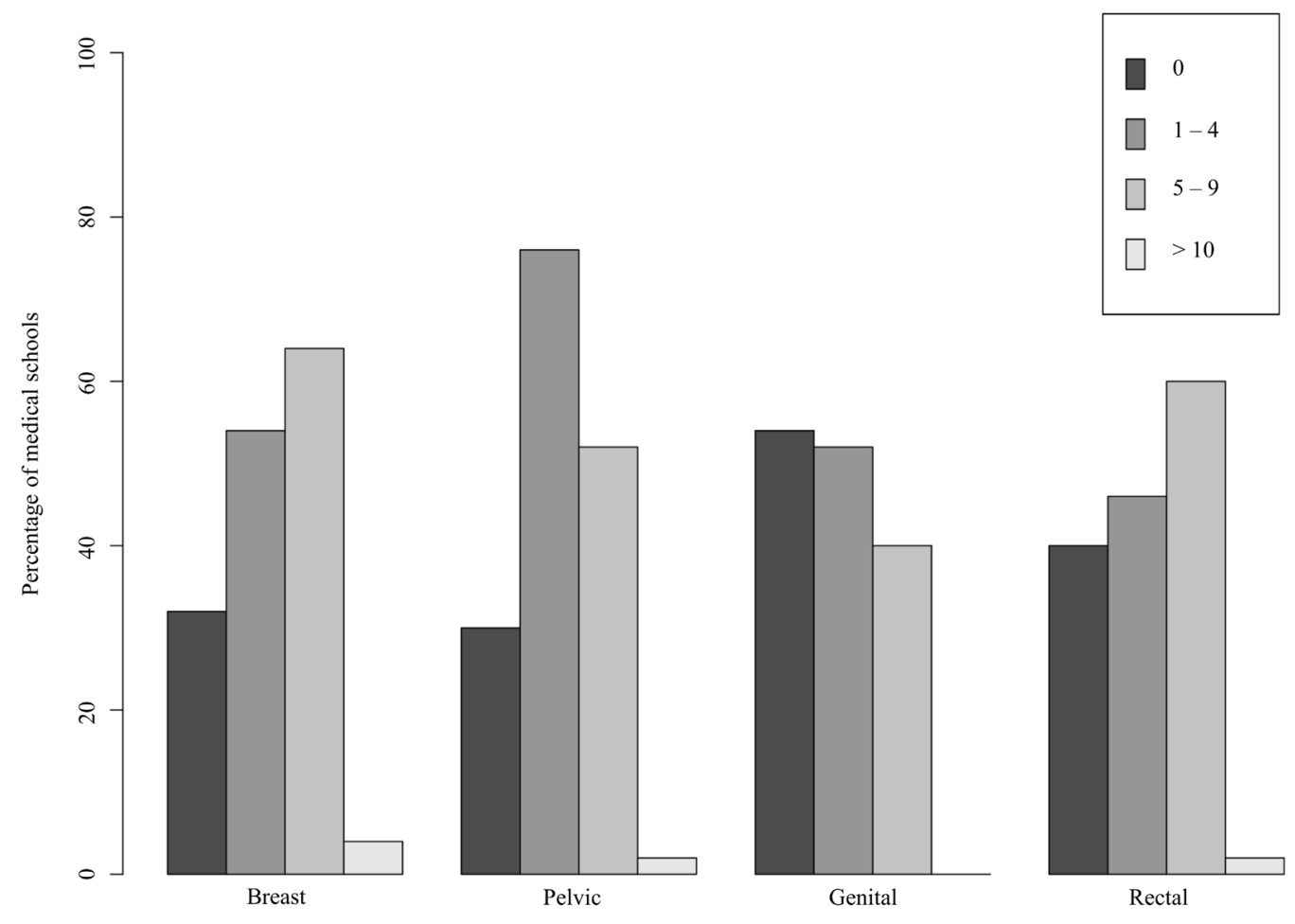

Type of Examination

Figure 5. Predicted number of examinations conducted by graduation. The percentage of surveyed medical schools predicting the number of breast, pelvic, male genital and female and male rectal examinations that would typically be performed by their medical students by the time of their graduation. 
used could be due to the fact that they allow repetition, provide an approximation of reality [5] and avoid exposing the patient to the risks inherent in the novice learning curve [13]. In the author's opinion they are also convenient and cost effective compared to teaching associates.

Teaching associates play a slightly lesser role, while real patients have a greater role, in the male genital (MG) and female and male rectal examinations (FMR) than in the female breast and female pelvic examinations. In the authors' opinion, this may be due to fewer advocates for urological teaching associate programs and the belief that manikins and real patients are sufficient for medical student training in the male genital and female and male rectal examinations. However this may not be ideal, as there is evidence that male teaching associates enhance confidence and improves both procedural and communication skills when teaching the rectal examination [8], and reduce student anxiety, particularly in female students, when teaching the male urogenital examination [19].

Most schools believed their students were confident in examination upon graduation, regardless of teaching method used. Perceived confidence with respect to teaching method showed no significant differences. In the author's opinion, possible explanations for such high reported confidence levels irrespective of teaching method include optimization of the specific teaching method or simply over-reporting. The perception of graduating student confidence is subjective. In the author's opinion there may also be an expectation on the part of the school that their graduating students will be confident in their sensitive examinations.

For the majority of schools, practice after the initial teaching sessions tends to be opportunistic rather than organized. Opportunistic practice of sensitive examinations on real patients varies considerably; hence some students may find they lack examination practice. Student gender is influential in the number of examinations performed on the opposite sex, with male students disadvantaged with respect to female pelvic and breast examination due to higher refusal rates by female patients $[4,20]$. Real patients are an unpredictable tool, with many patients deemed too unfit or are unwilling to be examined by medical students [21]. For these reasons alternative teaching methods must be explored.

Inter-country comparison of teaching methods demonstrates varying results, as detailed in the results section (Figures 1-4).

British medical schools favor using real patients and manikins, and have very low rates of teaching associate programs. In the present study, three British schools commented on their desire to instigate such a program but were hampered by several issues including limited funding and low staffing levels.
Australian schools used real patients and manikins extensively for teaching the rectal, breast and pelvic examinations (almost 90\% for each method in the latter two examinations), although $67 \%$ of schools also used teaching associates for the pelvic exam. They mostly used real patients in the genital exam (88\%). There were several positive comments about the Australian pelvic teaching associate programs, including the "dramatic" increase in student confidence and the enhanced "affective, cognitive and motor skills" of students leading to improved "confidence and competence". Other comments included the ability for the students to receive feedback on their skills and the opportunity to practice on a real person in a "safe" environment. The urological teaching associate pilot was also showing similar results.

Canadian schools tended to use manikins in their teaching of the sensitive examinations, particularly in the breast and rectal examinations (88\% and $75 \%$ respectively), although there was equal usage of teaching associate programs and manikins in the pelvic and genital examination ( $71 \%$ and $43 \%$ respectively). In this study there were several positive comments regarding the teaching associate programs, including the success in terms of introducing students to the examination of the breast and pelvis. One Canadian school commented that it used to have such a program to teach the female pelvic examination, and wished to re-institute this program.

The predominant mode of teaching the sensitive examinations in American schools is the teaching associate, with approximately two-thirds to three-quarters of all American using this method to teach the various exams. This was followed by manikin teaching (44\% - 60\%). This study revealed several favorable comments regarding the teaching associate sessions in American schools, including schools where there has been a similar course in the past and there are hopes of re-instituting this program. Other American schools remarked on the benefits of video demonstration and having students practicing in pairs, as well as the importance of professionalism in this context. A further comment from the present study noted the difficulty male students face gaining sufficient practice in the pelvic examination.

There is considerable anxiety and embarrassment regarding the performance of the sensitive examinations. These stem from factors such as "fear of missing a lesion" and "the intimacy of the examination" [22]. It remains unclear exactly how medical schools are dealing with these stressors. The teaching associate programs may provide the best opportunity, with $34 \%$ of schools surveyed incorporating this teaching during these sessions. The success of this combination is well supported in the literature, with many reports of reduction in student anxiety [23-26].

There are potential limitations with our study. Sources 
of bias include possible over-reporting or exaggerated emphasis of female sensitive examination teaching as compared to that of the male examination. This may be due to responder bias, with most school contacts being from the Obstetrics and Gynaecology department as they were the school personnel deemed most appropriate to answer the survey. However this was mitigated by many surveys being circulated to other departments such as Urology or General Surgery. Primary care physicians were not surveyed unfortunately. Another study weakness concerned the prediction of student confidencethis opinion was sought from medical school staff, and should have been validated by surveying the students. Despite our best efforts, our response rate was suboptimal. Finally, there were no questions regarding the signing off of opportunistic practice.

This study's strengths include the fact that it is a large survey involving many national and international medical schools, and it enquires about the teaching of all of the various sensitive examinations, associated stress reduction techniques and student confidence levels. Other studies in this field have surveyed the staff or students of individual medical schools, asking questions regarding only one sensitive examination subtype or stress reduction technique $[4,5,9]$. Further research is warranted in surveying national and international medical student experiences of the teaching of the various forms of the sensitive examinations, student confidence and suggestions for the optimal format for teaching the various sensitive examinations.

\section{REFERENCES}

[1] Posner, G. (2010) "Sensitive” examination workshop for medical clerkship students. MedEdPORTAL. https://www.mededportal.org/publication/7936

[2] Broadmore, J., Hutton, J.D. and Langdana, F. (2009) Medical students' experience of vaginal examinations of anaesthetized women. BJOG: An International Journal of Obstetrics \& Gynaecology, 116,731-733.

[3] Turner, K.J. and Brewster, S.F. (2000) Rectal examination and urethral catheterisation by medical students and house officers. Taught but not used. British Journal of Urology, 86, 422-426.

http://dx.doi.org/10.1046/j.1464-410X.2000.00859.x

[4] Akkad, A., Bonas, S. and Stark, P. (2008) Gender differences in final year medical students' experience of teaching of the intimate examinations: A questionnaire study. BJOG: An International Journal of Obstetrics \& Gynaecology, 115, 625-632.

[5] Siebeck, M., Schwald, B., Frey, C., Roding, S., Stegmann, K. and Fischer, F. (2011) Teaching the rectal examination with simulations: Effects on knowledge acquisition and inhibition. Medical Education, 45, 1025-1031. http://dx.doi.org/10.1111/j.1365-2923.2011.04005.x
[6] Naylor, R.A., Hollett, L.A. and Valentine, J. (2009) Can medical students achieve skills proficiency through simulation training? The American Journal of Surgery, 198, 277-282. http://dx.doi.org/10.1016/j.amjsurg.2008.11.036

[7] Bokken, L., Linssen, T., Scherpbier, A., Van Der Vleuten, C. and Rethans, J. (2009) Feedback by simulated patients in undergraduate medical education: A systematic review of the literature. Medical Education, 43, 202-210. http://dx.doi.org/10.1111/j.1365-2923.2008.03268.x

[8] Popadiuk, C., Pottle, M. and Curran, V. (2002) Teaching digital rectal examinations to medical students: An evaluation study of teaching methods. Academic Medicine, 77, 1140-1146.

http://dx.doi.org/10.1097/00001888-200211000-00017

[9] Bokken, L., Rethans, J. and Van Heurn, L. (2009) Students' views on the use of real patients and simulated patients in undergraduate medical education. Academic Medicine, 84, 958-963. http://dx.doi.org/10.1097/ACM.0b013e3181a814a3

[10] Behrens, A., Barnes, V.H. and Gerber, W.L. (1979) A model for teaching sophomore medical students the essentials of the male genital-rectal examination. Journal of Medical Education, 54, 585-587.

[11] Fang, W.L., Hillard, P.J. and Lindsay, R.W. (1984) Evaluation of students' clinical and communication skills in performing a gynaecological examination. J Med Educ, 59, 758-760.

[12] Wallis, L.A., Tardiff, K., Deane, K. (1984) Teaching associates and the male genitorectal exam. Journal of the American Medical Women's Association, 39, 57-62.

[13] Marsland, C., Larsen, P., Segal, R., Hunter, S., Morris, J., Mezzavia, P., et al. (2010) Proficient manipulation of fibreoptic bronchoscope to carina by novices on first clinical attempt after specialized bench practice. British Journal of Anaesthesia, 104, 375-381. http://dx.doi.org/10.1093/bja/aeq005

[14] Coldicott, Y., Pope, C. and Roberts, C. (2003) The ethics of intimate examinations-teaching tomorrow's doctors. British Medical Journal, 326, 97-101.

[15] Chang, E.H. and Power, D.V. (2002) Are medical students comfortable practicing physical examinations on each other? Academic Medicine, 75, 4, 84-89.

[16] Power, D.V. and Center, B.A. (2005) Examining the medical student body: peer physical exams and genital, rectal or breast exams. Teaching and Learning in Medicine, 17, 337-343. http://dx.doi.org/10.1207/s15328015tlm1704_5

[17] Rees, C., Wearn, A. and Vnuk, A. (2009) Don’t want to show fellow students my naughty bits: Medical students' anxieties about peer examination of intimate body regions at six schools across UK, Australasia and Far-East Asia. Medical Teacher, 31, 921-927. http://dx.doi.org/10.3109/01421590802578244

[18] O’Neill, P.A., Larcombe, C. and Duffy, K. (1998) Medical students willingness and reactions to learning basic skills through examining fellow students. Medical Teacher, 20, 433-436. 
http://dx.doi.org/10.1080/01421599880526

[19] Howley, L.D. and Dickerson, K. (2003) Medical students' first male urogenital examination: Investigating the effects of instruction and gender on anxiety. Medical Education, 8, 14. http://www.med-ed-online.org http://dx.doi.org/10.3402/meo.v8i.4336

[20] Powell, H., Bridge, J. and Eskesen, S. (2006) Medical students' self-reported experiences performing pelvic, breast and male genital examinations and the influence of student gender and physician supervision. Academic Medicine, 81, 286-289. http://dx.doi.org/10.1097/00001888-200603000-00022

[21] Olson, L.G., Hill, S.R. and Newby, D.A. (2005) Barriers to student access to patients in a group of teaching hospitals. Medical Education, 183, 461-463.

[22] Pugh, C.M. and Salud, L.H. (2007) Fear of missing a lesion: Use of simulated breast models to decrease student anxiety when learning clinical breast examinations. The American Journal of Surgery, 193, 766-770. http://dx.doi.org/10.1016/j.amjsurg.2006.12.033

[23] Siwe, L., Wijma, K. and Stjernquist, M. (2007) Medical students learning the pelvic examination: Comparison of outcome in terms of skills between a professional patient and a clinical model. Patient Education and Counseling, 68, 211-217. http://dx.doi.org/10.1016/j.pec.2007.05.007

[24] Wanggren, K., Patterson, G. and Csemiczky, G. (2005) Teaching medical students gynaecological examination using professional patients-Evaluation of students' skills and feelings. Medical Teacher, 27, 130-135.

http://dx.doi.org/10.1080/01421590500046379

[25] Abrahams, S., Chapman, M. and Taylor, A. (2003) Anxiety and feelings of medical students conducting their first gynaecological examination. Journal of Psychosomatic Obstetrics and Gynaecology, 24, 39-44. http://dx.doi.org/10.3109/01674820309042799

[26] Carr, S.E. and Carmody, D. (2004) Outcomes of teaching medical students core skills for women's health: The pelvic examination education program. American Journal of Obstetrics \& Gynecology, 190, 1382-1387. http://dx.doi.org/10.1016/j.ajog.2003.10.697 